\title{
Swot Analysis of Domestic Market of Wearable Sports Equipment Based on Internet of Things Technology
}

\author{
Y. Xu \\ Physical Education Institute \\ Weifang Medical University, China
}

\begin{abstract}
Using SWOT analysis on wearable fitness equipment market based networking technology, it can be drawn that: from the external environment, wearable sports equipment are facing opportunities and challenges, but the opportunities are more than challenges. From inside their own situation, there are both advantages and disadvantages, but the advantages outweigh the disadvantages. The research and development of Wearable sports equipment is the trend of the times, but it should be noted that the problem of insufficient demand and innovation.
\end{abstract}

Keywords-SWOT analysis; wearable sports equipment; Internet of Things

\section{INTRODUCTION}

At the end of 2014, national fitness had been promoted to national strategy. State Council put forward to major development of the sports industry. National governments called for the promotion of mutual integration of sports industry and other industries.[1]Government actively supports sports goods manufacturing industry to take new materials and technologies to enhance the quality level of the traditional sporting goods, especially to improve product technology. In many areas of the sports industry, wearable sports equipment deserved high hopes.

Wearable devices are those that continuity dressed in humans with advanced electrical systems, wireless networking and processing capabilities of the terminal device independent. Comprising two most important characteristics are long-term wearable and intelligent. According to industry application classification, wearable devices currently may be divided into five industries, including industrial, military, fitness and sports, entertainment, health and wellness. [2] According to market research firm Gartner estimated in 2014, wearable sports equipment worldwide shipments reached 70.2 million. There are other agencies are expected by 2018, the size of the market will reach $\$ 30$ billion. [3]

Well, it's how to develop scenarios, and it need the adequate market analysis. This requires SWOT market analysis. A SWOT analysis is a structured planning method used to evaluate the strengths, weaknesses, opportunities and threats involved in a project or in a business venture. [4]

\section{OPPORTUNITIES}

Opportunities are the elements that the project could exploit to its advantage. Generally, opportunities are often brought about form external political, economic, social and cultural environment.

\section{A. Rapidly Developing of Internet of Things Industry}

The Internet of Things (IOT) is the interconnection of uniquely identifiable embedded computing devices within the existing Internet infrastructure. Typically, Internet of Things is expected to offer advanced connectivity of devices, systems, and services that goes beyond machine-to-machine communications (M2M) and covers a variety of protocols, domains, and applications. [5] The interconnection of these embedded devices (including smart objects), is expected to usher in automation in nearly all fields, while also enabling advanced applications like a Smart Grid. [6]

1) Chinese Internet of Things industry planning: Currently, many countries has regarded the Internet of Things industry as to promote further economic indispensable growth in emerging industries. President Obama made a strong response to the IBM president proposed “Smart Earth”. ARRA signed by President Barack Obama for US provides a legal guarantee for Internet of Things industry. The EU has developed to promote the development of 14-point action plan for Internet of Things. Japan's U-Japan plans focuses on Internet of Things as one of four strategic areas. South Korea's IT839 strategy focuses on three things as one infrastructure. In an increasingly competitive international background, the Chinese government also promulgated "12th Five-Year Plan for Internet of Things” in 2012. It has also made it clear to develop broadband, convergence, security of the next generation of national infrastructure, promote the application of Internet of Things. Thanks to government support, Since then, the Chinese Internet of Things industry has entered a rapid development period.

2) Chinese Internet of Things industry development Status: According to US research Forrester firm predicts industrial value of Internet of Things brought 30 times bigger than the Internet, Internet of Things will be the next one trillion yuan level information industry businesses. Preview of Internet of Things Industry Research Institute according to market research group the latest data show that in 2012 China networking industry market reached 365 billion yuan, an increase of 38.6\% over 2011. In 2013, the market size of China's Internet of Things has achieved 489.6 billion yuan. [7] Some researchers predict that China Internet of Things overall market will reach 750 billion yuan in 2015, the annual compound growth rate of over $30.0 \%$. [8] 


\section{B. Sports Industry Ushers in the Golden Period of Development}

1) Sports industry development status: Foreign sports industry in the national economy proportion accounted for higher than China, such as the United States in 2013 amounted to 435 billion US dollars, accounting for 3\% GDP. South Korea accounted for $2.95 \%$, the UK, Germany and Japan have more than $2 \%$. However, China is currently $0.5 \%$. [9] Happily, this figure will soon be rewritten.

2) Sports industry development plan: Be included in the development of sports industry framework of economic and social development, the Chinese government has gradually become a major pillar of economic development. "Opinions on Accelerating the development of sports industry to promote sports consumption" put forward the total size of China's sports industry to be more than 5 trillion target in 2015, the economic contribution rate to rise to $0.5 \%$ from $1.3 \%$, the proportion of overall contribution to GDP of at least an increase of 0.8 points in space. Booming sports industry will bring help for wearable sports equipment market.

3) Wearable sports equipment domestic market: Wearable sports equipment worldwide shipments reached 70.2 million in the last year. A studies report that since 2014, China will boom as consumers wearable device for application, and continuous improvement in function related manufacturers and reduce the price under the impetus of the world's largest market. [10]Among them, wearable sports equipment has been the main driving force. A study from the same report indicates that, because Chinese consumers focus on health management attention, and the rapid development of application software, it will stimulate the rapid development of a tracking device worn style, with smart phones will inspire wisdom interconnected fast-growing demand for watches. China will become the world's largest market for wearable sports devices.

\section{National Lifestyle Changes}

1) Change in the way of everyday lifestyle: As society changes, people's lifestyles undergoing significant changes. The pursuit of health, science, civilized lifestyle has become a common social psychology. And now in China, fitness groups are everywhere.

Another significant lifestyle changes is the network deep in life. Internet has become an integral part of people's daily life content. The number of Internet users in China has reached 6.32 billions in 2004. [11] In the large population of Internet users, as well as more than five hundred million mobile phone users. These networks have been fully aware of the Internet has brought convenience. And they will become or have become potential customers of wearable devices.

2) Change in the way of sports lifestyle: Now people not only need to exercise, but also pursue to more fun and scientific exercise. More and more people abandon those boring or tasteless physical exercise, and devote to those interesting and obvious scientific guidance way of sports. Wearable sports equipment precisely meet these needs. It has very attractive for physical exercise enthusiasts. The largest sales of smart bracelet in China says it all.

\section{THREATS}

\section{A. Electronic Display Technology Barriers Exist}

Currently, smart sports watches, glasses and other wearable sports equipment and part of the phone began to use surfaces, flexible, flexible design. This need to be equipped AMOLED (Active Matrix/Organic Light Emitting Diode) display. South Korea's Samsung and LG are the major global supplier, while Chinese companies amount of market share of less than $10 \%$. In addition, some important aspects of the industry chain, such as sensors, interactive technology, sophisticated manufacturing technology and processes also need to upgrade.

\section{B. Privacy Issues}

In the era of Internet of Things, privacy security issues have been plaguing the industry. Since the core of wearable sports equipment technology is still Internet technologies. Therefore, whether safety of data collecting and the information transmission is questionable.

\section{Energy Consumption Issues}

Any electronic devices require a certain energy consumption, and wearable sports equipment is no exception. How to reduce energy consumption, cannot be ignored.

\section{Security Issues}

Security issue has been a byproduct of high-tech products. Face of all kinds of wearable sports equipment, it is not difficult to not have to worry about radiation, explosion and pollution, etc.. Along with general fitness movement in motion, whether the device safe and reliable is the problem that people focus on.

\section{E. Lack of Real Originality}

With respect to the higher level of technology innovation, product variety of foreign markets, local wearable product category in the domestic market is less, and homogeneity serious.

On the other hand, Because the actual technical route choice on substantially similar terms with the Internet and mobile Internet development path, the majority of local emerging wearable sports product actually still copying projects abroad, lack of real originality.

\section{STRENGTHS}

Strengthens refers to characteristics of the business or project that give it an advantage over others. The Internet Queen Mary Meeker prominent former Morgan Stanley analyst, who is now a partner in Silicon Valley venture capital firms KPCB's, published an Internet Report in 2013. In the book, she had made a detailed description of the advantages. She believes that the advantages of wearable devices can be hands-free, always-on, environment-aware, connected, attention-getting and development-platform. [12]Wearable sports equipment has in addition to the five advantages, but also has its own professional advantage. 


\section{A. Scene Experience}

Wearable sports equipment based on Internet of Things technology can provide any scenes set in advance, but this scene is often difficult to obtain in reality. For example, you are running on a treadmill, but you can "run into" the sand on the seashore. a Macy's fans can play together with Macy in the wearable sports equipment system, but in the traditional environment, this can only be a dream. You can also set a simulated environment to improve sports skills. Context Awareness occurs when the user's mobile device carried or worn around situation perception and presentation based on the specific environmental information, by providing a warning, or self-control, and control other devices.

\section{B. More Scientific}

1) Anytime and anywhere acceptable fitness guidance: Wearable sports equipment can not only collect information to monitor the course of the campaign but also can accept online, scientific and systematic fitness guide. This makes it easier to develop practitioners promote fitness habits, but also to enhance the fitness results.

2) Help coaches develop science training program: A good coach should let the players body more powerful, run more, shorter fatigue, avoid pain, and give the team a better result. One of the most experienced coaches might use the experience to make the right judgment, so the experience is invisible. But the experience is invisible, so only experience is not enough. On the contrary, it is multi-dimensional data can be quantified, and rely on trust. With more and more personalized data terminal, the amount of data increases, the more powerful server functions, so that the data change sports, and give it a new value and commercial value, not a distant thing.

3) Help referee objective and impartial verdict: Intense and tight race give the referees a lot of pressure. If the aid of wearable sports equipment, referee work will become easier and more accurate.

\section{More Interesting}

Because of having some great social pressure, people participate in sports to partial reduce the pressure. People want to experience more joy in exercise. Pleasure and healthy become the main purpose of fitness. One of the important function of wearable sports equipment provide participants with more pleasure.

\section{More Convenient}

Previously, when we want to measure the movement heart rate, blood pressure and other physiological indicators of human, we need to use much larger, bulky equipment, and often need to be completed in the laboratory. Now, some wearable sports equipment can easily achieve these seemingly impossible task.

\section{WEAKNESSES}

Although the last two years, wearable sports equipment swept the world, but also wearable smart devices has sparked all sorts of worries. Research sponsored by the Endeavour Partners shows that $1 / 3$ of wearable devices in American within six months is likely to be abandoned by the user. [13]These concerns reflect the wearable sports equipment have its inherent disadvantages.

\section{A. High Price and High Dependence}

Because of wearable sports equipment containing hightech and high added value, therefore higher prices occurs. It also limits the market demand wearable sports equipment.

Wearable sports equipment may make people overly dependent on technology. Like smart phones have done it, such devices will have a significant impact on people's communication, navigation and other aspects of efficiency, but also make people more obsessed with technology, easier to ignore the existence of the surroundings. When people interact with the digital world, lowering the threshold, people will definitely spend more time on it. We may indulge in them, and forget the real purpose of physical exercise.

\section{B. Low Profit}

Currently wearable device market is still in its infancy. Its chain is still being built at the beginning, and most remains still in the concepts and experiments. Therefore, high-yield products are less in the domestic market.

\section{Low Coverage}

Because of the high price and high technology content, therefore wearable sports equipment inevitably has low coverage. From the current situation, it is not a rigid demand commodity.

\section{SUMMARY}

The domestic development opportunity of wearable devices would be better than threat. Its advantage is obvious, the disadvantages cannot be ignored. Therefore, the relevant enterprises should seize the historical opportunity for development to increase research and development efforts, and actively guide consumption, with particular emphasis on innovation and demand, not blind development.

\section{REFERENCES}

[1] http://www.gov.cn/zhengce/content/2014-10/20/content_9152.htm

[2] Jim Li, http://www.eet-china.com/emag/1307_11_SL.html

[3] http://www.njdaily.cn/2015/0113/1029693.shtml

[4] SWOT analysis, http://en.wikipedia.org/wiki/SWOT_analysis

[5] J. Höller, V. Tsiatsis, C. Mulligan, S. Karnouskos, S. Avesand, D. Boyle: From Machine-to-Machine to the Internet of Things: Introduction to a New Age of Intelligence. Elsevier, 2014, ISBN 978-0-12-407684-6.

[6] O. Monnier: A smarter grid with the Internet of Things. Texas Instruments, 2013.

[7] http://news.xinhuanet.com/fortune/2014-06/03/c_1110971462.htm

[8] http://finance.sina.com.cn/roll/20130716/012516130396.shtml

[9] http://www.8264.com/viewnews-97642-page-1.html

[10] http://news.cnstock.com/news/sns_bwkx/201406/3059656.htm

[11] http://sh.people.com.cn/n/2014/0725/c176737-21772166.html

[12] http://www.askci.com/news/201406/11/1117839257037.shtml

[13] http://finance.chinanews.com/it/2014/04-09/6041860.shtml 